\title{
ANALISIS PREFERENSI KONSUMEN TERHADAP PRODUK TERASI UDANG
}

\author{
ROKHMAN PERMADI
}

Program Studi Agribisnis Fakultas Pertanian UNIVERSITAS DARWAN ALI

Jl. A. Yani No 1 Kuala Pembuang Kabupaten Seruyan Kalimantan Tengah

\begin{abstract}
ABSTRAK
The objectives of the research were to analyze the characteristics and consumers preference towards shrimp paste. Faktors and level attributes used are size (5 gr, 10gr and 25gr), presentation (burned, and have not burned), packaging (wrapper leaf, jointly and severally plastic, and aluminum foil) and purity (pure shrimp, and mixed fish). Respondents taken as many as 50 people with accidental sampling that will be required to determine the ranking of a combination of faktors and levels (stimuli) from most preferred to least preferred. Consumer characteristics were analyzed using descriptive analysis, and consumer preferences were analyzed with conjoint analysis. The results showed that the respondents prefer the paste to the size of $10 \mathrm{gr}$, had been burned, the packaging wrapper leaf, and pure shrimp paste. Based on the importance rate faktor, consumers prefer packing faktor for the first, and then the purity faktor, after that the size faktor, and the last is a representation faktor.

Keywords: Consumers, Preference, Shrimp Paste
\end{abstract}

\section{PENDAHULUAN}

Terasi merupakan salah satu hasil olahan (fermentasi) ikan dan atau udang yang sangat digemari oleh sebagian besar penduduk di Indonesia. Terasi biasanya dipakai sebagai bahan penyedap masakan seperti pada sayuran, rujak maupun disajikan sebagai sambal yang sangat populer di sebut sebagai sambal terasi. Meskipun terkesan sebagai "barang murah", terasi akhir-akhir ini semakin diminati masyarakat seiring dengan hadirnya menu-menu modern yang dikombinasikan dengan terasi.

Menurut data MARS Indonesia Tahun 2015 rata-rata pertumbuhan pasar terasi meningkat rata-rata $22,1 \%$ pertahun. Sedangkan nilai bisnis terasi mengalami peningkatan rata-rata $26,7 \%$ pertahun, dari $\mathrm{Rp} 220,8$ miliar pada Tahun 2008, hingga mencapai Rp 714,1 miliar pada tahun 2013 (MARS Indonesia, 2015).

Secara geografis wilayah Kabupaten Seruyan berhadapan langsung dengan laut jawa dengan berbagai macam sumberdaya perairannya. Data Statistik Kabupaten Seruyan menunjukkan bahwa sampai dengan Tahun 2014 produksi perikanan laut Kabupaten Seruyan sebesar $9.304,14$ ton $(53,71 \%$ dari total produksi perikanan), turun dari sebelumnya pada Tahun 2013 yang mencapai 11.172,90 ton.

Produksi terasi di Kabupaten Seruyan beberapa tahun terakhir mengalami tren meningkat setiap tahun. Menurut data Dinas Kelautan dan Perikanan Kabupaten Seruyan produksi terasi meningkat dari Tahun 2010 hingga Tahun 2014 (Tabel 1). Peningkatan produksi yang sangat signifikan terjadi pada Tahun 2014, hal tersebut karena Pemerintah Daerah Kabupaten Seruyan mencanangkan 
produk terasi sebagai produk unggulan dan produk khas Kabupaten.

Tabel 1. Data Produksi Terasi di Kabupaten Seruyan Tahun 2010-2014

\begin{tabular}{ccc}
\hline No & Tahun & Produksi (ton) \\
\hline 1 & 2010 & 34,95 \\
2 & 2011 & 35,60 \\
3 & 2012 & 36,38 \\
4 & 2013 & 39,27 \\
5 & 2014 & 159,56 \\
\multicolumn{2}{l}{ Sumber : Dinas Kelautan dan Perikanan Kabupaten Seruyan 2015 }
\end{tabular}

Berdasarkan konsep pemasaran, orientasi pemasaran adalah bagaimana produk yang dipasarkan dapat memuaskan kebutuhan dan keinginan konsumen. Sehingga pemasar atau produsen dituntut untuk mampu memasarkan atau memproduksi produk yang memiliki nilai yang unggul bagi konsumen. Swastha (2014) terdapat tiga unsur pokok konsep pemasaran yaitu : 1) Orientasi pada konsumen, 2) Penyusunan kegiatan secara integral, 3) Kepuasan konsumen. Menurut Kotler dan Keller (2009) Urutan penciptaan dan penghantaran nilai dapat dibagi dalam 3 fase: Pertama memilih nilai, pemasar harus mampu memilih dan menentukan nilai-nilai dari produk yang menjadi keinginan konsumen. Kedua menyediakan nilai, pemasaran harus menentukan fitur produk tertentu, harga, dan distribusi. Ketiga mengkomunikasikan nilai, dengan mendayagunakan tenaga penjualan, promosi penjualan, iklan, dan sarana komunikasi lain untuk mengumumkan dan mempromosikannya.

Memahami konsumen merupakan informasi pasar yang penting bagi sektor agribisnis agar dapat merencanakan, mengembangkan dan memasarkan produk dengan baik sehingga pada akhirnya dapat memberikan rekomendasi pada strategi pemasaran yang lebih efektif sesuai dengan kebutuhan konsumen. Dalam memahami konsumen, termasuk di dalamnya memahami bagaimana preferensi konsumen terhadap suatu produk yang akan ditawarkan. Merurut Kotler (2001) preferensi konsumen didefinisikan sebagai suatu pilihan suka atau tidak suka oleh seseorang terhadap produk (barang dan jasa) yang dikonsumsi.

Tujuan dari penelitian ini adalah :

1. Untuk menganalisis karakteristik konsumen terasi udang.

2. Untuk menganalisis preferensi konsumen terhadap produk terasi udang.

\section{METODE PENELITIAN}

Penelitian dilakukan dengan Metode Deskriptif eksploratif dengan maksud untuk mencari tahu lebih mendalam tentang suatu kasus untuk kemudian dapat memberikan suatu hipotesa. Metode pengambilan sampel menggunakan metode accidental sampling sejumlah 50 orang responden. Responden tidak dibatasi dari satu kota tertentu namun diambil dari berbagai macam kota sehingga diharapkan mampu mencerminkan preferensi secara umum sebagai target sasaran pemasaran terasi udang.

Karakteristik Konsumen akan dianalisis menggunakan analisis data deskriptif sedangkan preferensi konsumen akan dianalisis menggunakan analisis konjoin. Menurut Churchill (2005) analisis konjoin merupakan suatu teknik dimana nilai yang diberikan responden pada setiap atribut disimpulkan dari preferensi yang mereka ekspresikan terhadap berbagai kombinasi atribut. Pada dasarnya analisis conjoin berupaya menentukan manfaat-manfaat atau atribut- 
atribut mana yang akan dikorbankan pembeli untuk mendapatkan manfaatmanfaat atau atribut-atribut lainnya. Tujuan dasarnya adalah untuk menentukan kombinasi-kombinasi fitur mana yang paling disukai konsumen.

Proses analisis konjoin dilakukan dengan beberapa tahap sebagai berikut :

1. Menentukan Faktor (atribut spesifik) kemudian Level (bagian dari atribut) dari sebuah objek. Dalam penelitian ini yang menjadi Faktor dan Level adalah ukuran terasi (5 gr, 10 gr, dan 25 gr), penyajian terasi (Siap saji, dan tidak siap saji), kemasan (bungkus daun, renteng plastik, dan alumunium foil), dan kemurnian (murni udang, dan bercampur ikan).

2. Mendesain stimuli. Kombinasi antara Faktor dan Level disebut sebagai satu Stimuli atau Treatmen. Pendekatan yang akan digunakan untuk merancang stimuli yaitu kombinasi lengkap (full profile) atau evaluasi banyak faktor. Jumlah stimuli dapat dikurangi dengan menggunakan fractional faktorial design.

3. Mengumpulkan pendapat responden terhadap setiap stimuli yang ada. Responden mengevaluasi masing-masing stimuli dengan cara rating (memberi nilai peringkat), mulai dari stimuli yang paling diminati (dianggap penting) hingga stimuli yang paling tidak diminati (dianggap paling tidak penting)

4. Melakukan proses konjoin dari pendapat responden terhadap setiap stimuli, dilakukan proses conjoin untuk memperkirakan (prediksi) terasi yang diinginkan responden. Adapun secára umum model dasar analisis konjoin (Kuhfeld, 2000) adalah:

$$
Y_{i j}=\alpha_{0}+\sum_{i=1}^{m} \sum_{j=1}^{k} \alpha_{i j} x_{i j}+\varepsilon_{i j}
$$

Keterangan :

Yij : Peringkat seluruh responden

$\alpha 0$ : Intersep

$\mathrm{k}$ : Banyak taraf dari atribut ke-i

$\mathrm{m}$ : Jumlah atribut

xij : Peubah boneka atau variabel dummy dari atribut ke-i taraf ke-j

oij : Nilai kegunaan atribut ke-i taraf ke-j

eij : Galat

Dengan model regresi tersebut, maka dapat ditentukan nilai kegunaan dari taraf-taraf tiap atribut untuk menentukan nilai pentingnya suatu taraf relatif terhadap taraf yang lain pada suatu atribut. Setelah menentukan nilai kegunaan taraf, maka nilai kepentingan relatif (bobot) dapat dihitung dengan formula sebagai berikut:

$$
W_{i}=\frac{I_{i}}{\sum_{i=1}^{n} I_{i}}
$$

Keterangan :

$W i$ : Bobot kepentingan relatif untuk tiap atribut

$I i$ : Range nilai kepentingan untuk tiap atribut

5. Menentukan Predictive Accuracy (Ketepatan Prediksi) dari hasil konjoin di atas, yakni proses menguji hasil konjoin dengan sejumlah Holdout Sample 
untuk mengetahui apakah prediksi yang telah dilakukan memiliki ketepatan yang tinggi. Kuhfeld (2000) menyatakan ada beberapa ketentuan dalam melakukan interpretasi hasil, yaitu :

a. Taraf yang memiliki nilai kegunaan lebih tinggi adalah taraf yang lebih disukai.

b. Total nilai kegunaan masing-masing kombinasi sama dengan jumlah nilai kegunaan tiap taraf dari atribut-atribut tersebut.

c. Kombinasi yang memiliki total nilai kegunaan tertinggi adalah kombinasi yang paling disukai responden.

d. Atribut yang memiliki perbedaan nilai kegunaan lebih besar antara nilai kegunaan taraf tertinggi dan terendahnya merupakan atribut yang lebih penting.

\section{HASIL DAN PEMBAHASAN \\ Karakteristik Responden}

Tingkat pendidikan responden beragam dari tingkat pendidikan dasar sampai dengan pendidikan magister. Paling dominan responden berpendidikan SLTA/SMK/MA sebanyak 17 responden atau 34,00\%, kemudian yang telah menempuh pendidikan tinggi baik sarjana maupun pasca sarjana sebanyak 18 responden atau $36,00 \%$ dari total responden. Berdasarkan tingkat pendidikan, responden dianggap memiliki pendidikan yang lebih baik sehingga cara pandang dan cara pikir juga lebih baik. Pendidikan yang lebih baik akan mempengaruhi responden dalam memilih produk maupun merek dan dapat menentukan nilainilai yang lebih baik sesuai dengan kebutuhannya.

Jenis pekerjaan responden terdiri dari pegawai negeri, pegawai honorer, pegawai swasta, wiraswasta, dan ibu rumah tangga. Meskipun terdapat 14 orang responden sebagai ibu rumah tangga, sebenarnya mereka tidak benar-benar tidak memiliki pekerjaan. Terdapat beberapa responden yang sebenarnya juga memperoleh penghasilan diluar penghasilan kepala keluarga, namun karena jenis pekerjaannya dianggap tidak tetap maka mereka digolongkan pada kelompok pekerjaan sebagai ibu rumah tangga. Responden yang bekerja di sektor formal paling dominan sebagai pegawai negeri dan pegawai honorer sebanyak 25 orang atau $50,00 \%$.

Pendapatan responden yang paling dominan berada pada kisaran $<\mathrm{Rp}$ 700.000 perbulan sebanyak 21 orang atau $42,00 \%$, kemudian pada kisaran $\mathrm{Rp}$ 1.500 .000 - Rp 3.000.000 sebanyak 18 orang atau 36,00 \% dari total responden. Hanya terdapat 5 orang responden dengan penghasilan > Rp 3.000 .000 perbulan. 
Tabel 2. Karakteristik Responden

\begin{tabular}{lcc}
\hline \multirow{2}{*}{ Karakteristik } & \multicolumn{2}{c}{ Kuala Pembuang } \\
\cline { 2 - 3 } & Jumlah (orang) & Persentase (\%) \\
\hline Pendidikan & 9 & 18.00 \\
SD & 6 & 12.00 \\
SLTP/MTs & 17 & 34.00 \\
SLTA/SMK/MA & 11 & 22.00 \\
Diploma/Sarjana & 7 & 14.00 \\
Magister & & \\
\hline Pekerjaan & 15 & 30.00 \\
Pegawai Honorer & 10 & 20.00 \\
Pegawai Negeri & 8 & 16.00 \\
Pegawai Swasta & 3 & 6.00 \\
Wiraswasta & 14 & 28.00 \\
Ibu Rumah Tangga (IRT) & & \\
\hline Pendapatan (000) & 21 & 42.00 \\
< Rp 700 & 6 & 12.00 \\
Rp 700- Rp 1499 & 18 & 36.00 \\
Rp 1500- Rp 3000 & 5 & 10.00 \\
>Rp 3000 & &
\end{tabular}

Sumber : Pengolahan data primer 2016

\section{Preferensi Konsumen}

Hasil pembentukan stimuli secara full profil serta reduksi stimuli dengan fractional faktorial design agar mempermudah responden dalam menentukan ranking pada masing-masing stimuli diperoleh 9 profil stimuli seperti pada Tabel 3 berikut :

Tabel 3. Kombilasi faktor dan level hasil pengolahan menggunakan konsep orthogonal array

\begin{tabular}{cccll}
\hline Profil & Ukuran & \multicolumn{1}{c}{ Penyajian } & \multicolumn{1}{c}{ Kemasan } & \multicolumn{1}{c}{ Kemurnian } \\
\hline Stimuli 1 & 25 & Belum dibakar & Alumunium Foil & Murni Udang \\
Stimuli 2 & 25 & sudah dibakar & Bungkus Daun & Bercampur Ikan \\
Stimuli 3 & 10 & sudah dibakar & Alumunium Foil & Bercampur Ikan \\
Stimuli 4 & 10 & sudah dibakar & Renteng Plastik & Murni Udang \\
Stimuli 5 & 10 & belum dibakar & Bungkus Daun & Murni Udang \\
Stimuli 6 & 5 & sudah dibakar & Alumunium Foil & Murni Udang \\
Stimuli 7 & 5 & sudah dibakar & Bungkus Daun & Murni Udang \\
Stimuli 8 & 25 & sudah dibakar & Renteng Plastik & Murni Udang \\
Stimuli 9 & 5 & belum dibakar & Renteng Plastik & Bercampur Ikan \\
\hline Sumber : Diolah menggunakan software SPSS 16 & & \\
Berdasarkan uji korelasi menggunakan nilai korelasi Pearson's R dan \\
Kendall's Tau diperoleh nilai Pearson's R 0,977 dengan signifikansi 0,000 dan \\
nilai Kendall's Tau 1,000 dengan signifikansi 0,000 yang mengandung arti \\
terdapat hubungan yang kuat antara kombinasi atribut dengan preferensi \\
konsumen terasi udang melebihi nilai toleransi signifikansi 0,5. Hasil uji korelasi \\
data hasil penelitian dapat dilihat pada Tabel 3 berikut :
\end{tabular}


Tabel 3. Hasil uji korelasi data penelitian

\begin{tabular}{|c|c|c|}
\hline Kriteria & Value & Sig. \\
\hline Pearson's R & 0.977 & 0.000 \\
\hline Kendall's tau & 1.000 & 0.000 \\
\hline
\end{tabular}

Sumber : Pengolahan data primer 2016

Berdasarkan Tabel 4. Dapat dijelaskan bahwa faktor ukuran yang lebih disukai oleh responden adalah terasi dengan ukuran $10 \mathrm{gr}$ dapat dilihat dengan nilai Utility Estimated sebesar 0,340. Terasi dengan ukuran 10 gr dianggap cukup untuk penggunaan rumah tangga. Adapun faktor penyajian, responden lebih menyukai terasi yang sudah dibakar dengan nilai Utility Estimated sebesar 0,400. Konsumen memilih terasi yang sudah dibakar karena dianggap lebih praktis sehingga responden tinggal menggunakan terasi tanpa harus membakarnya lagi. Responden lebih menyukai terasi yang dikemas dengan kemasan atau bungkus daun dengan nilai Utility Estimated sebesar 0,120. Bungkus daun dingggap dapat meimbulkan aroma berbeda yang lebih digemari jika dibandingkan dengan kemasan yang terbuat dari bahan plastik dan alumunium foil. Sedangkan faktor kemurnian, ternyata responden lebih menyukai terasi yang tidak bercampur atau murni udang dengan Utility Estimated sebesar 1.085. terasi yang bercampur dengan ikan dianggap responden akan mengurangi citarasa khas dari terasi tersebut.

Tabel 4. Nilai kegunaan masing-masing faktor dan level

\begin{tabular}{llrr}
\hline \multicolumn{1}{c}{ Faktor } & \multicolumn{1}{c}{ Level } & Utility Estimate & Std. Error \\
\hline Ukuran & $5 \mathrm{gr}$ & -0.027 & 0.245 \\
& $10 \mathrm{gr}$ & 0.340 & 0.245 \\
& $25 \mathrm{gr}$ & -0.313 & 0.245 \\
\hline \multirow{2}{*}{ Penyajian } & Sudah dibakar & 0.400 & 0.184 \\
& Belum dibakar & -0.400 & 0.184 \\
\hline \multirow{2}{*}{ Kemasan } & Bungkus Daun & 0.120 & 0.245 \\
& Renteng Plastik & -0.033 & 0.245 \\
& Alumunium Foil & -0.087 & 0.245 \\
\hline Kemurnian & Murni Udang & 1.085 & 0.184 \\
& Bercampur Ikan & -1.085 & 0.184 \\
\hline
\end{tabular}

Sumber : Pengolahan data primer 2016

Important summary dari masing-masing faktor di tunjukkan oleh Gambar 1. yang menggambarkan tingkat kepentingan masing-masing faktor terhadap faktor lainnya. Supranto (2004), nilai kepentingan atribut tertinggi menunjukkan atribut tersebut lebih diperhatikan oleh konsumen daripada atribut-atribut lain dan taraf yang mempengaruhi preferensi konsumen dalam memilih produk yang akan dikonsumsinya. Secara keseluruhan responden lebih mementingkan penyajian dengan nilai kepentingan (Importance value) sebesar 28,654. Faktor berikutnya yang berada pada posisi kedua berdasarkan kepentingan keseluruhan responden adalah kemurnian dengan nilai kepentingan 27,168. Urutan kepentingan ketiga 
adalah kemasan dengan nilai kepentingan 23,526, dan yang terakhir berdasarkan kepentingan responden adalah faktor ukuran dengan nilai kepentingan 20,653.

Impertance summary

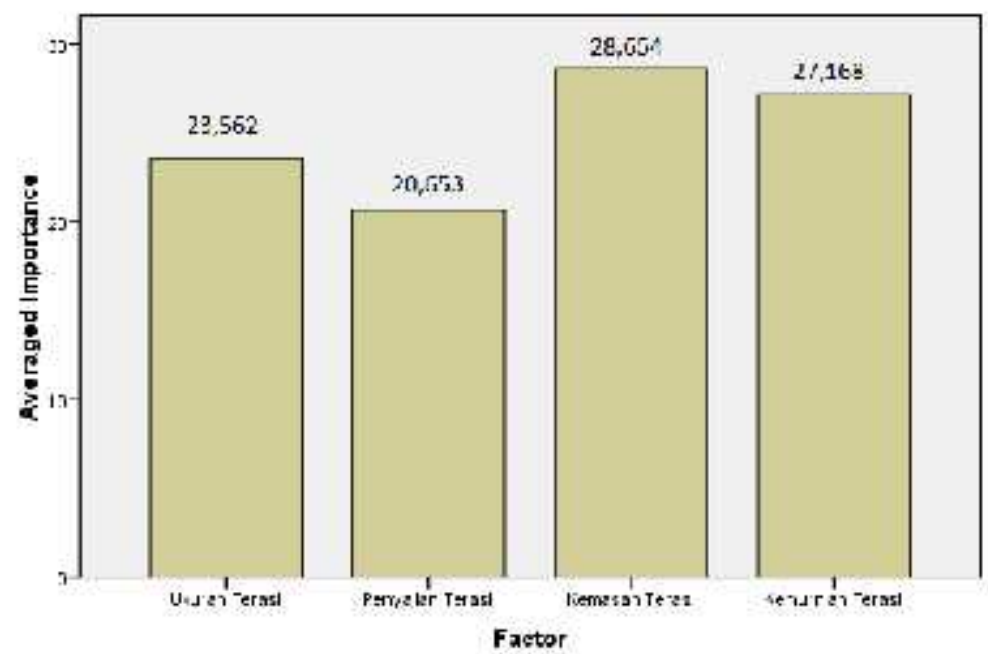

Gambar 1. Nilai kepentingan tiap faktor

Nilai preferensi konsumen terhadap masing-masing profil ditunjukkan dalam besarnya nilai kegunaan pada tiap profil, nilai tersebut mengindikasikan tingkat kesukaan responden terhadap profil stimuli tersebut. Secara umum, stimuli no 4 merupakan profil yang memiliki nilai kegunaan yang paling besar atau dalam artian kombinasi yang paling disukai oleh responden. Stimuli no 4 adalah terasi dengan ukuran 10 gr, sudah dibakar, kemasan renteng plastik, dan murni udang. Sedangkan profil yang paling tidak disukai adalah stimuli no 9 karena memiliki nilai kegunaan paling rendah. Stimuli no 9 merupakan kombinasi ukuran 5 gram, belum dibakar, kemasan renteng plastik, dan bercampur ikan. Nilai kegunaan profil stimuli dapat dilihat pada Gambar 2. berikut ini :

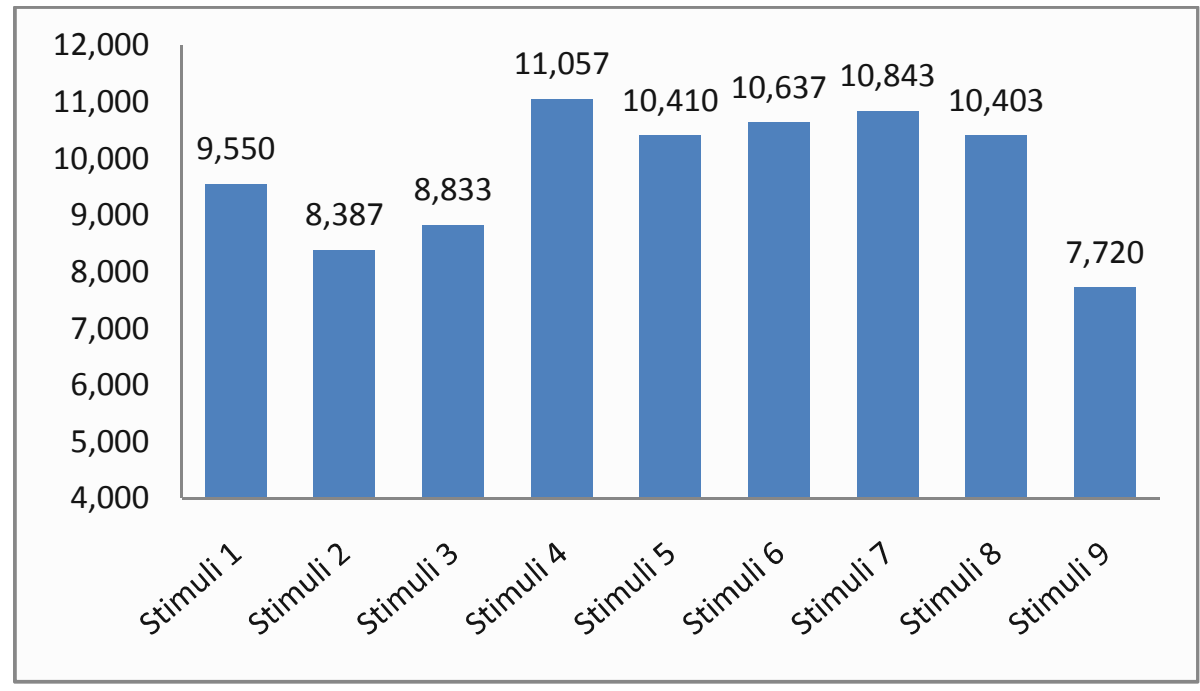

Gambar 2. Grafik nilai kegunaan total tiap profil 


\section{KESIMPULAN}

Berdasarkan hasil penelitian yang telah dilakukan dapat disimpulkan sebagai berikut:

1. Karakteristik konsumen berdasarkan tingkat pendidikan hampir semua responden $(70,00 \%)$ sudah menempuh pendidikan yang baik (sudah menempuh batas pendidikan wajib 9 tahun), hanya terdapat beberapa $(30,00 \%)$ yang tidak menempuh pendidikan wajib. Jenis pekerjaan responden $50,00 \%$ merupakan pegawai (negeri maupun honorer), sisanya sebagai pegawai swasta, wira usaha, dan ibu rumah tangga. 42,00\% responden berpendapatan $<\mathrm{Rp} 700.000$ dan $36,00 \%$ berendapatan Rp 1.500.00 - Rp 3.000.000

2. Responden lebih menyukai terasi dengan ukuran 10gr, sudah dibakar, kemasan bungkus daun, dan tidak bercampur atau murni udang. Sedangkan berdasarkan tingkat kepentingan faktor, konsumen lebih mengedepankan faktor kemasan, kemudian faktor kemurnian, setelah itu faktor ukuran, dan yang terakhir adalah faktor penyajian. Kombinasi yang paling banyak disukai adalah terasi dengan ukuran 10 gr, sudah dibakar, kemasan renteng plastik, dan murni udang.

\section{DAFTAR PUSTAKA}

Badan Pusat Statistik dan Badan Perencanaan Pembangunan Dearah. 2015. Seruyan Dalam Angka 2014. Kabupaten Seruyan.

Churchill, G.A. 2005. Dasar-dasar Riset Pemasaran Jilid 1. Penerbit Erlangga. Jakarta

Dinas Kelautan dan Perikanan. 2015. Profil Peluang Investasi dan Usaha Bidang Kelautan dan Perikanan. Kabupaten Seruyan

Engel, James F, Roger D. Blackwell, Paul W. Miniard. 1995. Perilaku Konsumen : Jilid 1 dan 2. Binarupa Aksara. Jakarta Barat.

Hair JF Jr, Black CW, Babin BJ, Anderson RE. 2010. Multivariate Data Analysis. Ed ke-7. New Jersey: Prentice Hall International

Kotler. 2000. Marketing Management: Analysis, Planning, Implementation and Control. Prentice Hall Int, Inc., Millenium Edition, Englewood Cliffs, New Jersey.

Kotler P \& Keller K.L. 2009. Manajemen Pemasaran. Edisi Ketiga Belas Jilid I. Penerbit Erlangga. Jakarta.

Kuhfeld WF. 2000. Conjoint Analysis Examples, SAS Institut, Inc. http://www. sawtooth software.com

MARS. 2015. Wanginya Bisnis Terasi di Indonesia. Diakses tanggal 10 Januari 2016 http://www.marsindonesia.com/newsletter/wanginya-bisnis-terasi-diindonesia

Nicholson \& Snyder, 2008. Micro Economic Theory. Basic principle and extensions. Thomson South-Western. USA

Prasetijo R, Ihalauw J.O.I J. 2005. Perilaku Konsumen. Andi Offset. Yogyakarta

Republik Indonesia. 1999. Undang-Undang Nomor 8 Tahun 1999 Tentang Perlindungan Konsumen. Sekertariat Negara. Jakarta

Simamora B. 2008. Panduan Riset Perilaku Konsumen. PT Gamedia Pustaka Umum. Jakarta

Sumarwan. 2011. Riset Pemasaran dan Konsumen ; Panduan Riset dan Kajian: Kepuasan, Perilaku Pembelian, Gaya Hidup, dan Persepsi Risiko. IPB Press. Bogor 
Swastha. B. 2014. Manajemen Pemasaran: Analisis Perilaku Konsumen. BPFE. Yogyakarta

Supranto, J. 2004. Analisis Multivariat Arti dan Interpretasi. Rieka Cipta. Jakarta. 